\title{
OVER DEN INVLOED VAN DE VERANDERDE VERHOUDING VAN GOUD TOT ZILVER OP DE DALING IN PRIJS BIJ ANDERE GOEDEREN.
}

-Het spreekt van zelf, dat ik noch de oorzaken van de daling in prijs van verschillende zaken, noch de muntkwestie, in haar geheelen omvang, binnen het bestek van dit tijdschrift kan bespreken. Ik wil alleen de aandacht vestigen op de volgende stukken:

10. Rapport van Mr. N. G. Pierson, voorkomend in de wSecond report of the Royal Cornmission on Gold and Silver 1888.)

2. Rapport van Prof. E. Nasse, te Bonn, voorkomend in hetzelfde stuk.

30. „De Muntkwestie in Nederlandsch Indië» door G. M. Boissevain, geplaatst in den Indischen Gids afl. Aug. en Sept. 1888.

44. „Das Sinken der Warenpreise während der letzte 15 Jahre» door Prof. E. Nasse, in de )Jahrbücher für National Economie van R. Hildebrand.» 1888.

In hun rapporten behandelen de heeren Pierson en Nasse de muntkwestie in 't algemeen, terwijl prof. Nasse, zooals de titel aanduidt, in het laatstgenoemd stuk meer de oorzaken van het dalen der prijzen behandelt. Beiden komen tot de conclusie, dat goud niet merkbaar in waarde gestegen is, en dat de daling der prijzen niet samenhangt met de muntkwestie. De heer Boissevain geeft een overzicht en kritiek van de brochures, in den laatsten tijd op Java verschenen over het muntwezen in onze Oost-Indische bezittingen. Eoor. 1888. 
Hij gelooft wel aan de goudschaarste, en aan haar invloed op de prijzen.

In hetgeen hier volgt zal ik niet die schrijvers op den voet volgen. Ik zal alleen releveeren, wat mij voorkomt voor de lezers van dit tijdschrift hef meest van belang te zijn.

Het is bekend, dat de waardeverhouding tusschen goud en zilver onderling in de laatste jaren veranderd is. Terwijl tot in 1866 een Engelsch once zilver waard was ongeveer 61 pence in goud, variëert die waarde in de laatste jaren tusschen 43 en 50 . $\mathrm{Nu}$ kan die verandering veroorzaakt zijn door een daling van de waarde van het zilver of door een stijging van de waarde van het goud; ook misschien door beiden. Om dit uit te maken moet men nagaan, hoe de prijsverhouding is van goud en zilver tot andere zaken. En als men nu ziet, dat niet alleen zilver maar bijna alle andere zaken, vergeleken met goud, in waarde verminderd zijn, dan ligt de conclusie voor de hand, dat het goud zelf in waarde gestegen is. Wil men dit niet aannemen, dan moet men de reden aanwijzen voor de waardevermindering van zilver en van die andere zaken.

Voor zilver is de oorzaak van de daling gemakkelijk aan te geven. De productie van zilver is in de laatste jaren toegenomen, en de behoefte aan zilver, de vraag, is sterk verminderd. Die mindere vraag vindt haar oorzaak hierin, dat in Nederland en in de landen van de Latijnsche muntunie, namelijk Frankrijk, Italië, België en Zwitserland, de vrije aanmunting van zilver verboden is, terwijl Duitschland en de Scandinavische rijken den gouden standaard hebben aangenomen en groote bedragen zilver hebben ontmunt.

In verband hiermede wordt door sommigen o. a. ook door den heer Boissevain (p. 48) aangenomen, dat goud in waarde moet gestegen zijn. De Vereenigde Staten van Noord-Amerika en de landen, die den gouden standaard aannamen, hebben, naar schatting, van 1871 
tot 1885 voor $\mathbf{5 1 0}$ millioen gulden meer goud tot zich getrokken dan van de goudproductie gedurende die jaren disponibel was. Dit cijfer is belangrijk als men in aanmerking neemt, dat de geheele voorraad gouden munt en muntmateriëel, die voorhanden was in 1885 in Europa, Amerika en Australië, geschat wordt op 7900 millioen gulden.

Maar wanneer door bovengenoemde oorzaak het goud in waarde gestegen was, dan zou zich dat hebben moeten openbaren op twee manieren: $1^{\circ}$. in den minderen voorraad van goud, in de behoefte aan goud als ruilmiddel; $2^{n}$. in de verhooging van den rentestandaard, doordien de behoefte aan ruilmiddel, aan goud, grooter werd. En dit zou het eerst merkbaar moeten geweest zijn bij de circulatiebanken der verschillende landen; want alle vraag of aanbod van metaal concentreert zich bij die banken. ')

Geen van beiden is echter het geval geweest in de laatste jaren. De voorraad goud bij de banken en in de schatkist van al de staten is, naar schatting ${ }^{2}$ ), van 1877 tot 1885 gestegen van 1740 millioen gulden tot 3024 millioen. En de rentestandaard is in doorsneê bij bijna alle banken in Europa in de laatste 10 jaren lager geweest dan vroeger.

Dit meerdere goud bij de banken moet gekomen zijn, doordien het goud, dat in handen van het publiek, in circulatie was, langzamerhand door inwisseling tegen bankbiljetten in banden van de banken is overgegaan, of liever, doordien bij credietvraag aan de banken geen spetie, maar bankbiljetten gevraagd wordt. De behoefte aan goud voor de betalingen bij het publiek moet verminderd zijn. Het spreekt van zelf, dat, als de meerdere vraag naar goud voọr landen, die den gouden standaard aannamen, samenviel met mindere behoefte aan goud in alle landen te zamen, dat dan die meerdere vraag

3) Nasse, pag. 259.

2) Nases, ibidem. 
geen schaarste aan goud kon doen ontstaan, en dat daardoor het goud niet in waarde kan zijn toegenomen.

$\mathrm{Nu}$ zou men kunnen beweren, dat die banken genoodzaakt waren geweest, dit meerdere goud tot zich te trekken, om te voldoen aan den regel, dat $c^{\mathrm{B}} 1 / 3$ van hare biljetten door metaal gedekt moet zijn. Dat die noodzakelijkheid $\mathrm{n}$ i e $\mathrm{t}$ bestond blijkt uit de twee volgende feiten.

Vooreerst uit het feit, reeds door mij genoemd, dat de rentestandaard in de laatste jaren lager was dan vroeger. En toch is verhooging van rente altijd het middel, waardoor de banken haar voorraad goud trachten te versterken.

Het tweede feit, waaruit blijkt dat er overvloed van goud bij de banken was, is dit, dat het bedrag ongedekte bankbiljetten bij de banken niet is toegenomen. Als een bank tegen 100 metaal, dat zij bezit, 300 aan bankbiljetten kan uitgeven, kan zij bij een voorraad van 200 metaal 600 aan bankbiljetten uitgeven. Wanneer wij nu zien, dat het totaal der ongedekte bankbiljetten bij alle banken te zamen is afgenomen van 4000 millioen gulden in 1875 , tot 2500 millioen gulden in 1885 , 1) dan blijkt daaruit dat de banken in het laatste jaar minder behoefte aan metaal hadden dan in het eerste. Als dus in de laatste jaren de goudvoorraad bij de banken is toegenomen, dan kan dat niet veroorzaakt zijn doordien de banken haar goudvoorraad opzettelijk hebben versterkt, maar doordien er meer goud was, dan het publiek voor de circulatie noodig had. Hierin ligt dus een bewijs, dat er geen goudschaarste was.

Daarbij moet bovendien in 't oog gehouden worden, dat in landen met dubbelen standaard, zoo als Holland en de landen van de Latijnsche muntunie, het zilver, ofschoon intransiek in waarde gedaald, voor zijn nominale waarde dezelfde dienst doet als goud, voor dekking van de daartegen uitgegeven bankbiljetten, evengoed als voor de circulatie bij het publiek. In die landen is de depre-

1) Zie Neumaun Spallart aangehaald door Piersou, p. 254. 
ciatic van het zilver dus zonder invloed. De procentsgewijze invloed van minderen aanvoer van goud op de circulatie moet in die landen omgeslagen worden, niet alleen over den totalen voorraad goud, maar over den totalen voorraad goud en zilver.

Uit de twee feiten, boven aangehaald, blijkt, dat er in de laatste jaren minder behoefte aan goud als ruilmiddel ontstaan is, en dat de vraag naar goud van die landen, die tot den gouden standaard zijn overgegaan, geen invloed op het geheel gehad heeft 1 )

Dat in de laatste jaren steeds minder spetie (goud of zilver) en steeds meer bankbiljetten, voor de betalingen gebruikt worden, ziet iedereen in zijn omgeving. In de stad mijner inwoning heb ik dit eenigsints onder cijfers kunnen brengen, door op te maken hoe de verhouding was bij de betalingen in de Kassierszaak, waarvan ik deelgenoot ben. De betalingen geschiedden dáár: in 1840 voor 55 pCt. in bankbiljetten; voor 45 pCt. in spetie

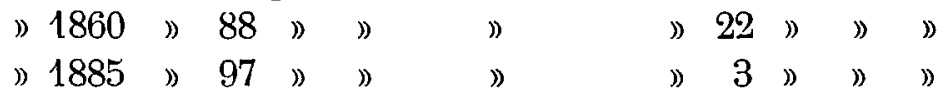

Daarin ligt de verklaring van het feit, dat de circulatie van bankbiljetten bij de Nederlandsche Bank zoo is toegenomen, zoo als uit het volgende blijkt. De spetie is uit de circulatie naar de Bank gegaan. Bijna iedereen betaalt met bankbiljetten in plaats van met specie.

1840

1860

1885
Bankbiljetten in omloop.

ff $23,772,000$

) $98,576,000$

) $197,614,000$
Voomaad munt bij de N. Bank.

$$
\begin{array}{rr}
f & 18,038,000 \\
》 & 52,395,000 \\
\text { 》) } & 121,174,000
\end{array}
$$

1) Het is mij niet duidelijk hoe Mr. Pierson (pag. 254) kan zeggen, dat in de lastste 15 jaren de prijzen der goederen gedaald kummen zijn door de vermindering van de circulntie van ougedekte bankbiljetten. Ik kan mij voorstellen dat de prijzen dalen door gebrek an ruilmiddel, omdat dan de rente verhoogd moet worden, of cloordien de circulatie-banken minder dan vroeger kapitaal kumen voorschietev. Manr als de ongedekte circulatie vermindert terwijl de goudvoomaad is tregenomen, blijkt draruit dat or geen zoo groote behoefte aan ruilmiddel is; darvan zou eerder een rijzing der prijzen liet gevolg moeten zijn. 
Naarmate er minder spetie en meer bankbiljetten voor de betalingen gebruikt wordt, voorziet de zelfde kwantiteit spetie in een grooter bedrag aan betalingsmiddelen omdat tegen 100 spetie 300 bankbiljetten kunnen uitgegeven worden. De rol, die de spetie bij de betalingen speelt, wordt in de laatste jaren steeds kleiner. Een vermeerdering of vermindering van den voorraad goud heeft dus steeds minder invloed op de prijzen.

Maàr ook het gebrưk van bankbiljetten neemt niet toe in verhouding 'van de uitbreiding van de handelstransactiën in de laatste jaren, omdat het crediet steeds meer gebruikt wordt bij de verrekening onderling tusschen kooplieden. Men weet, dat in Engeland bij de kolossale betalingen van den handel, niet alleen geen spetie maar zelfs geen bankbiljetten gebruikt worden. Men betaalt dáár met een kassiersbriefje, een cheque, op zijn bankier; en hij, die dit ontvangt, bezorgt het ook weer bij zijn eigen bankier. De bankiers onderling verrekenen die cheques; en het saldo, dat de eene bankier aan den ander door die verrekening schuldig is, wordt betaald door overschrijving van de rekening bij de Engelsche Bank van den eenen bankier op den ander.

Buiten Engeland maakt die eenvoudige manier van betaling nog weinig vordering. Maar toch neemt ook dáár het gebruik van crediet toe. $\mathrm{Zij}$ die goederen uitzenden naar elders, en zij die goederen van elders ontvangen, gebruiken voor die zaken meer dan vroeger de tusschenkomst van de bankiers. De wissels, die het gevolgzijn van die transactiën, worden door de Bankiers onderling in rekening courant verrekend, en circuleeren minder bij het publiek. Het is éen bekend feit in de handelswereld, niet alleen hier maar ook elders, dat de wissels, door den eenen handelaar op den ander getrokken, veel minder in handen van het publiek komen dan vroeger.

Het $\mathrm{c}$ r e d i e t vervangt al meer en meer de circulatiemiddelen, zoodat hierdoor geneutraliseerd wordt de betrek- 
kelijke vermindering van goud als circulatiemiddel 1). En dat crediet werkt ook bij de betalingen van de eene natie aan de andere, waarvoor anders goud noodig is. Ook hierbij verrekenen de bankiers onderling de wissels, de pretentien van het eene land op het andere. Verder worden er effecten gezonden, door de zoogenaamde arbitrage in fondsen, of men geeft tijdelijke dekking voor saldo's. Alleen wanneer de aanzuivering van het saldo, dat het eene land aan het andere schuldig is, wat lang duurt, wordt goud gebruikt tot afbetaling.

Dat er goudschaarste zou bestaan, en dat deze van grooten invloed zou zijn op de prijzen, wordt dus door de meesten, m. i. terecht, ontkend.

Daarentegen is het zeker, dat bijna alle zaken in de laatste jaren sterk in prijs gedaald zijn. Men weet, hoe dit in cijfers gebracht is. De Engelsche Economist maakt daarvan sedert jaren een statistiek, door de prijzen van 22 hoofdartikelen in Engeland bijeen te tellen, en dan de optelling van die prijzen, die zij (index numbers» noemt, van de verschillende jaren te vergelijken. Later heeft men de prijzen in Duitschland, niet van 22, maar van 114 artikelen bijeengeteld, om een toevallige rijzing of daling van enkele artikelen niet te veel op het totaal te doen influenceeren. Nog later heeft men getracht elk artikel naar zijn meerder of minder belang te laten mede telle elk artikel in een land werd in- of uitgevoerd. Maar de uitkomst van alle berekeningen is, dat in doorsneê de meeste artikelen in de laatste jaren 15 à 20 pCt. in prijs gedaald zijn. Wat kan nu daarvan de oorzaak zijn?

Daarvoor is niet ééne oorzaak, maar dit is het gevolg van een samenvallen van verschillende omstandigheden.

Een hoofdoorzaak is wel de vermeerdering en het goedkooper worden van de middelen van transport. Zoo heett men berekend, 1) dat bij tarwe het vervoer van het

(1) Nasse pag. 260 , 
binnenland van Engelsch-Indië naar Engeland sedert 1873 verminderd is van $/ 13.60$ per Quarter tot $/ 6.05$. Van het binnenland van Amerika naar Engeland van $f 8$ tot $/ 2.80$. Dit maakt dus een verschil van $/ 5$ á $f 7$ per Quarter. De prijzen van tarwe zijn in Engeland gevallen van $/ 35.20$ tot $\int 21$ per Quarter, dus een verschil van ruim /14 of c. 40 pCt. - Zoo als het met tarwe is, is het met een menigte andere artikelen gegaan.

Maar er is meer. Door die verbetering van communicatiemiddelen kan el nu op plaatsen geproduceerd en van dáár uitgevoerd worden, die vroeger afgesloten waren; en dit niet alleen in transatlantische plaatsen, maar ook binnen Europa. Wanneer vroeger iets in het achterland van Duitschland goedkooper dan hier geproduceerd werd, kwamen die goederen toch hier duurder te staan dan het inlandsch product, omdat de kosten van transport zoo zwaar drukten. Nu die transportkosten zoo kolossaal verminderd zijn, wordt die aanvoer mogelijk en komen zij, aangevoerd op de plaats van consumtie, dikwijls goedkooper te staan dan de prijs vroeger was toen $\mathrm{zij}$ op die plaats geproduceerd werden. Het terrein van productie van verschillende artikelen is daardoor zeer sterk uitgebreid; zij worden, nu de afstand geen hinderpaal meer is, geproduceerd waar dit het goedkoopst kan geschieden; dat de prijzen daardoor gedaald zijn, spreekt van zelf. Omgekeerd profiteeren ook onze eigen producenten daardoor; want ook hunne artikelen hebben door die lagere transportkosten een veel grooter markt, en daardoor een grooteren afzet gekregen.

Behalve de kosten van transport zijn in de laatste jaren alle handelsonkosten verminderd, doordien de kooplieden zich met minder winst op elke transactie tevreden stellen, en in grooter omzet vergoeding zoeken. Ook het vermijden van tusschenpersonen heeft op de prijzen invloed gehad.

(3) Secoud Report Ruygl Commission p. 252. 
Eindelijk is door de verbetering in de machines niet alleen het transport goedkooper geworden, maar, wat nog van grooter invloed is, de fabrikage zelve geschiedt daardoor met veel minder kosten en veel meer in 't groot. En doordien de wetenschap geleerd heeft, dat nog met voordeel iets gefabriceerd kan worden uit hetgeen vroeger als afval bij de fabrikage beschouwd werd, zooals bv. de glycerine bij de kaarsenfabrieken, de bijproducten bij de gasfabrieken, zoo kan daardoor het oorspronkelijk fabrikaat goedkooper geleverd worden.

Mijn bestek gedoogt niet meer in bijzonderheden te treden. Wie van nabij met den handel en het fabriekwezen bekend is, zal dadelijk toestemmen, dat er een menigte oorzaken zijn voor den lageren prijs der goederen, geheel afgescheiden van de muntkwestie. Dat landerijen in prijs gedaald zijn, spreekt van zelf, nu de producten van het land minder waard zijn. Maar dat de grond niet in prijs gedaald is doordien het goud in waarde gestegen is, blijkt hieruit, dat gronden in de steden, geschikt voor het bouwen van huizen, bijna overal sterk in waarde zijn vooruitgegaan.

Het bovenstaande vindt men grootendeels terug in de aangehaalde stukken van Nasse en Pierson. Ik gevoe] daardoor vrijheid, om van meening te verschillen met een zoo bekwaam schrijver als de heer Boissevain, die, trouwens met vele andere mannen van gezag, blijft hechten aan de verlaging der prijzen door appreciatie van het goud.

De heer Boissevain behandelt in het bovenaaangehaald stuk hoofdzakelijk een andere kwestie. Hij recenseert eenige brochures, in den laatsten tijd op Java verschenen, over de vraag, of het wenschelijk is in onze 0.-Indische bezittingen den zilveren standaard in te voeren, evenals die in Engelsch Indië bestaat. De heer B. gelooft niet, dat die invoering wenschelijk is; maar hij erkent de waardevermindering, de depreciatie, van het zilver; en met zijn 
overtuiging van appreciatie van het goud, geeft hij toe, dat de planters on Java daardoor schade geleden hebben. Hoe die schade door de vermeerdering van de waarde van het goud ontstaan zou zijn, kan het gemakkelijkst duidelijk gemaakt worden door na te gaan, hoe de planters in Engelsch Indië, naar men beweert, voordeel gehad hebben door de daling van de zilverprijzen.

Toen vroeger het zilver nog niet in prijs gedaald was, kreeg, afgescheiden van de vracht, die de kooper betaalde, de planter in Eng. Indië, als hij zijn product te Londen voor 100 pond sterling goud verkocht, daarvoor 923 rupees zilver: toen de koers van de rupee was 2 shilling 2 pence. Wanneer hij $\mathrm{nu}$ datzelfde product voor denzelfden prijs te Londen verkoopt, krijgt hij voor die 100 pond st., nu de koers 1 shilling $51 / 2$ pence is, 1372 rupees, omdat het zilver vergeleken met goud in waarde gedaald is. $\mathrm{Nu}$ beweert men, dat in Engelsch Indië de dagloonen niet hooger geworden zijn. Als dit waar is, als dus de planter aldaar hetzelfde aantal rupees aan werkloon betaalt, en hij krijgt voor zijn product zooveel meer rupees terug, dan maakt hij een kolossaal voordeel.

De tarwe te Londen is echter, zooals ik boven opgaf, meer in prijs gedaald, dan het verschil in vracht tusschen vroeger en $\mathrm{nu}$ is. Hij krijgt dus niet die volle winst, waarvan ik sprak. Maar de planter in Engelsch Indië is er toch oneindig beter aan toe dan die op Java. Want de laatste krijgt ook minder dan vroeger door de daling van vele artikelen, maar hij mist dat voordeel van de koers, dat de planter in Engelsch Indië heeft. Omdat het zilver c 30 pCt. in waarde gevallen is vergeleken met goud, krijgt de planter in Eng. Indië 130 in zilver tegen de planter op Java 100 in goud. Als nu beide hetzelfde werkloon blijven betalen als vroeger, dan heeft de planter op Java een nadeel van $30 \mathrm{pCt}$. op zijn werkloon vergeleken met dien in Engelsch Indië 
Het is zelfs nog veel erger op Java, zoo wordt beweerd. Als het waar is, dat goud in waarde is to egenomen dan zijn de prijzen der Javaproducten gedaald, doordien zij in goud betaald worden. En als de planter aldaar hetzelfde werkloon als vroeger moet betalen, dan verliest hij daarop nog bovendien.

Velen willen nu op Java den zilveren standaard ingevoerd zien. Het gevolg daarvan zou zijn, dat de koers van Java op Holland 30 pCt. zou stijgen. Men zou op Java, als de suiker bv. voor $/ 8$ per pikol naar Holland verkocht werd, daarvoor op Holland trekkend, f 10.40 in zilver op Java krijgen. Als dan vroeger op een picol suiker bv. 5 werkloon betaald moest worden, en als dat loon hetzelfde bleef, dan zou hij $/ 5.40$ overhouden, tegen vroeger $f 3$.

In een ander opzicht heeft de planter, zoo wordt beweerd, nog een voordeel. Als hij vroeger ontvangen voorschotten moet terugbetalen, en hij krijgt zooveel meer voor zijn product, dan valt hem die afdoening zooveel gemakkelijker.

Het laatste is waar: als hij dat voorschot op Java terug moet betalen. Dat voordeel heeft niet alleen de planter, maar iedereen, die vroeger gecontracteerde schulden moet afbetalen. De oorzaak hiervan is zeer eenvoudig. De invoering van den zilveren standaard zou eenvoudig zijn, het deprecieeren, het minder waard maken, van het betaalmiddel. Op dit oogenblik heeft de gulden de waarde van één tiende van een gouden tienguldenstuk, omdat men tien guldens kan inwisselen tegen $/ 10$ aan goud. Maar wordt de zilveren standaard ingevoerd, dan gaat de gulden circuleeren tegen zijn waarde als zilver, dat is voor 30 pCt. minder; dan is de gulden niet meer waard dan $1 / 14^{\mathrm{d} \theta}$ van een gouden tienguldenstuk. Wanneer ik nu schuld, vroeger gecontracteerd, ga af betalen met een andere munt, dan waarin ik gecontracteerd heb, dan ontneem ik eenvoudig zooveel aan mijn crediteur, 
als ik er bij win. Hetzelfde onrecht doet men aan het werkvolk als men het loon niet verhoogt, terwijl alle artikelen, die het koopen moet, in prijs gestegen zijn na de verzwakking van de munt, waarin betaald wordt, en waarvan de werkgever wil profiteeren.,

Die winst voor den planter bij het terugbetalen van vroeger ontvangen voorschotten zal echter alleen dan bestaan, als hij die terugbetaling op Java moet doen. Muet hij die voorschotten in Nederland terug betalen, dan verdwijnt dit voordeel. Want daar de koersen op Europa, zoo als ik zeide, zich richten naar die depreciatie, moet hij, om $f 100$ in Nederland te betalen, misschien $f 130$ in zilver op Java betalen.

Dat door de invoering van den zilveren standaard op Java de bevolking grootendeels het gelag zou betalen, wordt door sommige schrijvers op Java met zeker cynisme erkend. Anderen willen den overgang verzachten, door die depreciatie over enkele jaren te verdeelen. De heer Boissevain, ofschoon hij niet vóór de invoering van den zilveren standaard op Java is, zegt, dat, als men dit doen wilde, de meest rechtvaardige manier voor alle partijen deze zou zijn, dat men den gulden zóóveel zwaarder maakte als noodig zou zijn, om hem werkelijk in waarde gelijk te doen zijn met één tiende van een gouden tienguldenstuk. Maar hiermede zou men op Java niet tevreden zijn, omdat dan juist voor de planters het voordeel zou verdwijnen, waarvoor zij den zilveren standaard verlangen.

De heer Boissevain heeft met groote helderheid de meeningen en wenschen van de verschillende schrijvers van die Indische brochures uiteengezet. Zoo als ik zeide, hij gelooft aan appreciatie van het goud en schrijft voor een gedeelte daaraan toe de daling van de prijzen der goederen, in tegenstelling van de meening 0 . a. van Pierson en Nasse. Op één punt vind ik zijn betoog minder duidelijk. 1) Hij gelooft niet aan een 7.00 groote zilver-

(1) Pag. 54. 
depreciatie in Engelsch-Indië, en vindt daarvan o. a. een bewijs hierin, dat de invoeren van zilver in EngelschIndië niet zóó groot geweest zijn, als zij bij een depreciatie van zilver hadden moeten zijn. Ik geloof, dat hij niet genoeg in het oog houdt, dat bij een depreciatie van de munt de koersen der wissels op het buitenland zich daarnaar regelen, en dat uit- of invoer van metaal alleen dan plaats heeft, als de koersen niet proportioneel veranderen. Als bv. 1000 sovereigns van hier naal Londen gezonden, mij, met alle kosten inbegrepen, kosten / 12130, en ik kan daartegen een wissel van 1000 pd. st. op Londen verkoopen, die mij tegen den koers van / 12.16 opbrengt / 12160, dan ligt er voordeel in, die transactie te doen. Maar als de koers f 12.13 is, zal niemand er aan denken. Evenzóó is het met den uitvoer van zilver naar Engelsch Indië. Als zilver hier in prijs daalt, dạ zal men alleen dan zilver uitvoeren, als de koers op Indië niet in proportie verandert. Maar de neiging van de koersen is altijd naar iets boven of beneden het punt, waarop in- en uitvoer van metaal mogelijk wordt. De wisselkoersen op Eng. Indië regelen zich te Londen geheel naar de zilverprijzen; in Eng. Indië is dit evenzoo. Als nu door den onvoordeeligen koers in Eng. Indiě; de exporteurs in Europa minder goederen uitzenden naar Indië, dan kan, voor een oogenblik, door minder aanbod van wissels op Indië, de koers stijgen, en uitvoer van zilver mogelijk worden. Maar dit herstelt zich spoedig weder, omdat in Indië, door minder aanvoer van goederen, de prijs dier goederen dáár stijgt. Dan nemen de uitvoeren uit Europa weer toe, en is dus geen uitvoer van zilver meer mogelijk, want dan komt de wisselkoers weer op het normale punt, waarop uitvoer van zilver geen voordeel geeft. In het feit, dat de uitvoeren van zilver naar Eng. Indië niet bijzonder zijn toegenomen, ligt dus geen bewijs voor de stelling, dat zilver in Eng. Indië niet gedeprecieerd is. 
Ik mag niet meer van het geduld van den lezer vergen, en moet mij bij het bovenstaande bepalen al is dit zeer oppervlakkig. Nu het derde rapport van de Engelsche muntcommissie eerlang verschijnen zal, kan ieder, die in de muntkwestie belang stelt, het vóór en tegen der verschillende meeningen op nieuw nagaan. Ik hoop alleen door het bovenstaande de belangstelling van sommigen te hebben opgewekt, en de lust, om de boven door mij aangebaalde stukken te lezen.

Rotterdam, 10 Nov. 1888.

M. MEES.

Nadat het hovenstaande geschreven was, kwam inij het Final Report van de Royal Commission in handen. Met zeldzame bekwaamheid en volledigheid is daarin verzameld wat vóór, en tegen, de verschillende meeningen te zeggen is. Vooral de voorstanders van de meening, dat goud in waarde gestegen is, en dat van bimetallisme alleen heil te wachten is, hebben meer krachtige argumenten dan vroeger in 't veld gebracht. Wie deze stukken leest, zal meer en meer de overtuiging krijgen, dat men zich er voor wachten moet, een of ander verschijnsel in den economischen toestand aan een enkele oorzaak toe te schrijven; dat men bij alles letten moet op den storenden invloed in verschillende richting van bijkomende omstandigheden. Het is onmogelijk met zekerheid te zeggen, dat een of ander feit door een bepaalde oorzaak ontstaan is.

Zoo is de lage rentestand niet altijd een bewijs van overvloed van goud. Wanneer de prijzen der goederen dalen, vermindert de kooplust. Dan hebben velen, die anders hun kapitaal gebruiken om goederen te koopen, dat kapitaal disponibel, en bieden het aan op de geldmarkt voor korte beleggingen. Daardoor daalt de rentestandaard. Het kan zijn, dat in dienzelfden tijd veel goud van de bank gevraagd wordt, maar dat de bank niet 
verplicht is haar rente te verhoogen, omdat er bij haar geen geld gevraagd wordt door den handel. Het omgekeerde komt ook voor. Als de prijzen stijgende zijn, en als dan de kooplust ontwaakt, vragen velen geld ter leen, om daarmede goederen te koopen. Dan kan de rente stijgen, ook al heeft de bank goud in overvloed.

Uit het bovenstaande is het duidelijk, dat de rentestandaard niet alleen beheerscht wordt door de meerdere of mindere vraag naar goud, maar ook door de vraag naar kapitaal. Want het is kapitaal dat ter leen gevraagd wordt, als gelden worden opgenomen, om daarmede goederen te koopen. Maar als men nu ziet, dat de voorraad goud bij de banken steeds is toegenomen, en dat de rente laag geweest is, dan is het wa a rs chijnl ij k, dat er geen goudschaarste is.

Diezelfde onzekerheid over de juiste oorzaak bestaat ook bij de rijzing of daling van de prijzen der goederen. Een daling $\mathrm{k}$ an ontstaan door vermindering van koopkracht of kooplust, door stijging van de waarde van het ruilmiddel, door vermindering van de kosten van productie en vervoer etc. Maar wanneer men weet, dat niet alle zaken in prijs gedaald zijn, en dat bij vele artikelen de kosten van productie of vervoer verminderd zijn, dan is het waarschijnlijk, dat die daling niet veroorzaakt is door apprecatie van het goud.

Met alle bescheidenheid geloof ik, dat men, door het voortdurend beschouwen van de muntkwestie, daaraan veel te hoog gewicht is gaan hechten, wat haar invloed op de prijzen van goederen betreft. .Het spreekt van zelf, dat er verband is tusschen den voorraad geld, en de prijzen der goederen, in geld uitgedrukt. Maar een toename of vermindering van den voorraad geld of muntmetaal heeft m. i. niet direct zoo grooten invloed op de prijzen, omdat, zoo als ik boven aantoonde, voor de betalingen van grootere sommen dikwijls geen spetie of bankbiljetten noodig zijn. Wel zullen velen zich met mij herinneren, 
dat het, kort na de goudontdekkingen in 1851 , de algemeene opinie was, dat geld in waarde zou dalen, dat alles duurder zou worden. Toen werd door velen land gekocht tot prijzen, die weinig rente lieten, maar in ' $t$ vooruitzicht, dat men in korte jaren, door de stijging der prijzen, veel met dat land zou verdienen. - Maar in den handel gelden die consideratiën niet. Dáár werkt men in den regel niet op lange termijnen, maar dáár koopt men in de hoop, dat binnen enkele weken de prijzen zullen stijgen. Ontstaat eens die opinie, ook al is die weinig gemotiveerd, dan gaan alle prijzen hooger. Naar den voorraad goud bij de Bank, of naar den rentestandaard wordt door den koopman veel minder gezien, dan men denkt. Wel is dit het geval bij de prijzen der effecten. Een zeer groote kwantiteit effecten zit in handen van personen, die ze gekocht hebben met geleend geld, met het oug op het voordeel dat er is in het verschil in de rente, die zij van de effecten trekken, met de rente die zij voor het opgenomen geld betalen; anderen koopen met geleend geld eenvoudig in de hoop van stijging van de koersen. Voor beiden is een mogelijke verhooging van den rentestandaard bij de Bank van grooten invloed op de kans van winst.

Terwijl dus bij effecten de prijzen zeker geinfluenceerd worden door meerdere of mindere goudschaarste, geloot ik niet, dat dit in die mate bij goederen het geval is. Maar dit is zeker, dat men zeer voorzichtig moet zijn met het trekken van conclusiën, en dat men nooit verder zal komen, dan de meest waarschijnlijke oorzaken aan te wijzen. Eéne zaak staat vast, dat die zaken in vergelijking met anderen goedkooper worden, bij welke $\mathrm{d}_{\mathrm{e}}$ kosten van productie en van vervoer lager geworden zijn.

M. M. 